Research Paper

\title{
The Diagnostic Value of Serum IGFBP7 in Patients with Esophageal Squamous Cell Carcinoma
}

\author{
Xinyi Huang1†, Chaoqun Hong2†, Yuhui Peng1,3,4†, Shihan Yang5, Lisheng Huang6, Cantong Liu', Liuyi \\ Chen ${ }^{1}$, Lingyu $\mathrm{Chu}^{3}$, Liyan $\mathrm{Xu}^{3,4,7 凶}$, Yiwei $\mathrm{Xu}^{1,3,4 \bowtie}$ \\ ${ }^{1}$ Department of Clinical Laboratory Medicine, the Cancer Hospital of Shantou University Medical College, Shantou 515041; ${ }^{2}$ Department of Oncological \\ Laboratory Research, the Cancer Hospital of Shantou University Medical College, Shantou 515041; ${ }^{3}$ The Key Laboratory of Molecular Biology for High Cancer \\ Incidence Coastal Chaoshan Area, Shantou University Medical College, Shantou 515041; ${ }^{4}$ Guangdong Esophageal Cancer Research Institute, Shantou University \\ Medical College, Shantou 515041; ${ }^{5}$ Department of Dermatology and Venereology, Shantou Central Hospital, Shantou 515041; 6 Department of Radiation \\ Oncology, the Cancer Hospital of Shantou University Medical College, Shantou 515041; IInstitute of Oncologic Pathology, Shantou University Medical College, \\ Shantou 515041, China. \\ tThese authors contributed equally to this work.
}

$\square$ Corresponding authors: Yiwei Xu, Department of Clinical Laboratory Medicine, the Cancer Hospital of Shantou University Medical College, Shantou 515041, PR China; Email: yiwei512@126.com; telephone number: +86-159-8970-1200. Correspondence may also be addressed to Liyan Xu, E-mail: lyxu@stu.edu.cn.

(c) Ivyspring International Publisher. This is an open access article distributed under the terms of the Creative Commons Attribution (CC BY-NC) license (https://creativecommons.org/licenses/by-nc/4.0/). See http://ivyspring.com/terms for full terms and conditions.

Received: 2018.12.18; Accepted: 2019.05.01; Published: 2019.06.02

\begin{abstract}
Esophageal squamous cell cancer (ESCC) is one of the leading malignant cancer in the world and especially in China with high incidence and mortality. The exploration of novel serum biomarkers is required for early detection of ESCC. We investigated the diagnostic value of serum insulin like growth factor binding protein 7 (IGFBP7) in ESCC, evaluating its potential to improve the diagnosis of ESCC. The serum samples of 106 patients with ESCC and 107 normal controls were tested by enzyme-linked immunosorbent assay (ELISA). The levels of IGFBP7 in ESCC group were significantly higher than that in normal controls, compared by the Mann-Whitney $U$ test $(P<0.000 I)$. Using receiver operating characteristic $(R O C)$ curve, the diagnostic value of serum IGFBP7 was demonstrated. Versus normal group, the area under the ROC curve (AUC) of all ESCC was $0.794(95 \% \mathrm{Cl}$ : $0.735-0.853)$ and early-stage ESCC was $0.725(95 \% \mathrm{Cl}: 0.633-0.817)$. With optimized cutoff value of 2.993 $\mathrm{ng} / \mathrm{mL}$, IGFBP7 showed certain diagnostic value with specificity of $90.7 \%$, sensitivities of $40.6 \%$ and $32.4 \%$ in ESCC and early-stage ESCC, respectively. Considering the correlation between clinical data and IGFBP7, no significant association was found (all $P>0.05$ ). Thus, we supposed that serum IGFBP7 might be a potential biomarker in the diagnosis of ESCC.
\end{abstract}

Key words: esophageal squamous cell carcinoma, IGFBP7, serum, biomarker, diagnosis.

\section{Introduction}

Esophageal cancer (EC) is a malignant solid tumor. It ranks seventh in incidence and sixth in mortality overall cancers according to a status report worldwide. Specifically, this cancer would be responsible for an estimated 1 in every 20 cancer deaths in $2018{ }^{[1]}$. As for another report from China [2], $\mathrm{EC}$ is the sixth most prevalent cancer and the fourth leading cancer-related deaths in China in 2014. There is a higher incidence and mortality in male than that in female, both worldwide and in China [1,2]. EC consists of two main histological types, including esophageal squamous cell carcinoma (ESCC) and adenocarcinoma. In the western world, most of esophageal cancer cases are considered as adenocarcinoma [3,4], compared to ESCC, the predominant histological type in China [5]. Moreover, the low 5-year survival rate, which is about $15 \%-25 \%$ worldwide ${ }^{[6]}$ and $30.3 \%$ in China ${ }^{[7]}$, is deemed to the result of diagnosis delay because there is no ideal detection for EC up to now ${ }^{[6,8]}$. Thus, better diagnosis is in urgent need of efficient detection to improve the early-diagnostic rate.

Serum biomarker has a conceivable prospect in application [9]. Nowadays, accurate identification of tumors depends on the examination histopathologically after biopsy mostly. In terms of digestive tract tumor, biopsy is carried out if exceptional findings are observed during endoscopy, 
which is widely used in screening and diagnosis [10]. Because of uneconomic and invasive property and poor tolerance [11,12], people seldom apply to be checked by endoscopy until symptoms occur, resulting in delay of diagnosis. Like the early diagnosis rate of ESCC in the present study was only $34.9 \% \quad(95 \% \mathrm{CI} \quad 26.1 \%-44.9 \%)$, demonstrating unfavorable prognosis of cancer ${ }^{[8]}$. The emergence of serum biomarkers could be a potential solution to improve the diagnosis. As reported, Protein $\mathrm{Z}$ can improve the diagnosis of ovarian cancer (OC), increasing the area under the receiver operating characteristic (ROC) curve (AUC) from 77\% for carbonhydrate antigen 125 alone to $81 \%$ for Type I and from $76 \%$ to $82 \%$ for Type II OC [13]. The combination of four serum proteins-carcinoembryonic antigen (CEA), retinol binding protein, alpha1-antitrypsin, and squamous cell carcinoma antigen (SCCA) were found to have a diagnostic value for lung cancer with sensitivity of $89.3 \%$ and specificity of $84.7 \%$ [14]. Serum epidermal growth factor receptor has the diagnostic performance in oral cancer with AUC of 0.71 [15]. Cysteine-rich 61 could distinguish colorectal cancer from normal controls with AUC of 0.935 , sensitivity of $83 \%$ and a specificity of $97 \%$ based on cutoff of $92.0 \mathrm{pg} / \mathrm{mL}$ [16]. Alpha-fetoprotein [17,18], CEA [19] and carbohydrate antigen 19-9 [20,21] are widely used in clinical practice to suspect the existence of hepatocellular carcinoma, colorectal cancer and pancreatic cancer, respectively, assisting and guiding the final diagnosis. Some traditional markers in clinical use, such as CEA, cytokeratin 19 fragment 21-1 and SCCA, were evaluated in the diagnosis of ESCC but exhibited a low value to detect ESCC [22-24]. Therefore, we would like to explore a more ideal marker for ESCC in present study.

Insulin-like growth factor binding protein 7 (IGFBP7) is a secreted protein, belonging to the family of insulin-like growth factor binding protein and a part of the insulin-like growth factor axis, which has great effects on the growth, differentiation and proliferation of mammalian cells [25]. The expression of IGFBP7, reportedly, is closely related to cancers such as lung cancer, prostate cancer and so on [26, 27]. In particular, the expression of IGFBP7 at tissue or cellular levels revealed relationship with esophageal cancer in previous studies [28-30]. As far as we know, the relationship between serum IGFBP7 and ESCC, especially about the diagnostic value is rarely reported. Combined with noninvasive characteristics, this study explored the diagnostic value of serum IGFBP7 in ESCC, expecting to obtain an ideal marker for detection of ESCC.

\section{Methods}

\section{Population}

From May 2015 to February 2017, 213 serum samples, including 106 ESCC samples and 107 normal controls, were collected from the Cancer Hospital of Shantou University Medical College. The gender in the control group were well corresponded and age was relative matched with those in the ESCC group (Table 1). Cases of the cancer group were all newly diagnosed patients without any tumor-related treatment before blood collection. The serum samples of normal controls were collected from the people who did the physical examination in the hospital and no evidence of cancer had been detected. The serum samples were collected by centrifugation at $2500 \mathrm{~g}$ for 10 minutes after intravenous blood sampling and then stored at $-80^{\circ} \mathrm{C}$ until the day before experiment. The present work was approved by the institutional review board of the Cancer Hospital of Shantou University Medical College and in accordance with the Declaration of Helsinki. With informed consents, all participants in both groups voluntarily joined this study.

The diagnosis of ESCC was confirmed histopathologically and staging is aligned with the Eighth Edition of the American Joint Committee on Cancer (AJCC) Cancer Staging Manual [31]. AJCC TNM stage 0+I+IIA was defined as early-stage while IIB+III+IV as advanced-stage as our previous study [32].

\section{Enzyme-Linked Immunosorbent Assay (ELISA)}

We detected the serum concentration of IGFBP7 by ELISA. The procedure was conducted in line with user manual of the ELISA kit (Cusabio, CSB-E17249h). Briefly, reagents, samples and standards were prepared as instructed. The concentrations of the IGFBP7 standards for creating a standard curve were $0,156,312,625,1250,2500,5000,10000$ pg/mL. Serum samples to be used were removed from $-80^{\circ} \mathrm{C}$ before test. We diluted the samples with sample diluent in a ratio of $1: 3$ as it was the preferable ratio when we explored in the preliminary experiment. After preparation, $100 \mu \mathrm{l}$ standard and sample were added to each well and then incubated at $37^{\circ} \mathrm{C}$ for 2 hours. After removing the liquid but no washing, 100 $\mu \mathrm{l}$ Biotin-antibody $(1 \mathrm{X})$ was added to each well and then incubated at $37^{\circ} \mathrm{C}$ for 1 hour. Then, aspiration and washing were embarked on for 3 times by microplate washer (Microplate washer 888, Thermo Fisher Scientific, Vantaa). 100 $\mu 1$ horseradish peroxidase (HRP)-avidin (1X) was added to the washed well and the plate was put at $37^{\circ} \mathrm{C}$ for 1 -hour incubation. Next, 
aspiration and washing were conducted for 5 times. $90 \mu 1$ 3,3',5,5'-tetramethyl benzidine (TMB) substrate and $50 \mu \mathrm{l}$ stop solution were added to each well for optical density (OD) test. Incubation of 20 minutes at $37^{\circ} \mathrm{C}$ was done after TMB substrate was added. The OD value was read at $450 \mathrm{~nm}$ and $570 \mathrm{~nm}$ wavelength within 5 minutes after adding stop solution (Multiskan ELX800, BioTek Instruments, Winooski). All serum samples were tested with 2 replicates and averaging was performed for analysis. OD values (Table S1) were converted into concentration, which were obtained by plotting a standard curve with a four-parameter logistic curve manner and multiplied by the dilution factor.

Table 1. Participant information and clinicopathological characteristics

\begin{tabular}{|c|c|c|}
\hline Group & ESCC patients $(n=106)$ & Normal Controls $(n=107)$ \\
\hline \multicolumn{3}{|l|}{ Age, years } \\
\hline Mean \pm SD & $60 \pm 7$ & $54 \pm 9$ \\
\hline Range & $42 \sim 77$ & $40 \sim 76$ \\
\hline \multicolumn{3}{|l|}{ Gender } \\
\hline Male & 75 & 74 \\
\hline Female & 31 & 33 \\
\hline \multicolumn{3}{|l|}{ Smoke } \\
\hline Yes & 68 & 47 \\
\hline No & 38 & 60 \\
\hline \multicolumn{3}{|l|}{ TNM stage } \\
\hline 0 & 3 & \\
\hline I & 13 & \\
\hline II & 28 & \\
\hline III & 47 & \\
\hline IV & 15 & \\
\hline \multicolumn{3}{|l|}{ Histological grade ${ }^{*}$} \\
\hline High (grade 1) & 31 & \\
\hline Middle (grade 2) & 54 & \\
\hline Low (grade 3) & 13 & \\
\hline \multicolumn{3}{|c|}{$\begin{array}{l}\text { Depth of tumor invasion ( } \mathrm{T} \\
\text { staging) }\end{array}$} \\
\hline Tis & 3 & \\
\hline T1 & 11 & \\
\hline T2 & 21 & \\
\hline T3 & 34 & \\
\hline $\mathrm{T} 4$ & 37 & \\
\hline \multicolumn{3}{|c|}{$\begin{array}{l}\text { Regional lymph nodes (N } \\
\text { staging) }\end{array}$} \\
\hline No & 58 & \\
\hline N1 & 29 & \\
\hline N2 & 14 & \\
\hline N3 & 5 & \\
\hline \multicolumn{3}{|l|}{ Metastasis } \\
\hline M0 & 106 & \\
\hline M1 & 0 & \\
\hline \multicolumn{3}{|l|}{ Tumor Size } \\
\hline Mean \pm SD & $3.8 \pm 1.6$ & \\
\hline Range & $1 \sim 8$ & \\
\hline \multicolumn{3}{|l|}{ Tumor Site } \\
\hline Upper thorax & 14 & \\
\hline Middle thorax & 70 & \\
\hline Lower thorax & 22 & \\
\hline
\end{tabular}

\section{Statistical Analysis}

The obtained data were computed and analyzed with Microsoft Excel, SPSS (version23.0), Sigma Plot
10.0 and GraphPad Prism 7.0 software statistically. 95\% exact confidence interval (95\% CI) estimation were shown for the positive rate of each group. The differences of IGFBP7 level between ESCC group and normal group, early-stage ESCC and normal group were tested by performing Mann-Whitney $U$ test. The positive rates of serum IGFBP7 between/among the subgroups categorized by different clinical data were compared using chi-squared tests. Using ROC curve plotting, accuracy of diagnostic value was analyzed, which could be evaluated through the sensitivity, specificity and AUC. On the premise of specificity above $90 \%$, we chose the cutoff value by maximizing the sensitivity in coordinates of the curve and minimizing the distance of the corresponding point in ROC curve (ESCC group versus normal controls) to the top-left corner. The specificity of above $90 \%$ was chose as the premise because that could produce a test used for early detection with health economically viable application ${ }^{[33]}$. When $P$ value was less than 0.05 (two-sided), the test result was considered as a statistically significant difference.

\section{Results}

\section{The level of serum IGFBP7 in ESCC patient and normal controls}

The mean concentration of serum IGFBP7 was $1.932 \pm 0.079 \mathrm{ng} / \mathrm{mL}, 3.074 \pm 0.133 \mathrm{ng} / \mathrm{mL}$ and $2.663 \pm$ $0.167 \mathrm{ng} / \mathrm{mL}$ in normal group $(\mathrm{n}=107)$, ESCC group $(\mathrm{n}=106)$ and early-stage ESCC group $(\mathrm{n}=37)$, respectively (Table 2). As first impression, the distribution of ESCC and normal controls is different. ESCC accounts for more histogram volume on higher concentration while normal groups for more lower concentration (Figure 1A). For better observation on distribution and degree of dispersion, the levels of serum IGFBP7 in three groups were shown in scatter plot (Figure 1B) and box plot (Figure 1C). As shown in Figure 2AB and Table 2, the level of serum IGFBP7 in ESCC was higher than that in normal controls, which was confirmed statistically $(P<0.0001)$. The difference between early-stage ESCC and normal controls is also significant $(P<0.0001)$.

Table 2. Comparison between three groups.

\begin{tabular}{lllll}
\hline & $\mathrm{N}$ & Mean \pm SD & $P^{*}$ value & Positive $(\%, 95 \% \mathrm{CI})$ \\
\hline ESCC & 106 & $3.074 \pm 0.133$ & $<0.0001$ & $43(40.6,31.3-50.6)$ \\
Early-stage ESCC $(0+\mathrm{I}+\mathrm{IIA})$ & 37 & $2.663 \pm 0.167$ & $<0.0001$ & $12(32.4,18.6-49.9)$ \\
Normal controls & 107 & $1.932 \pm 0.079$ & & $10(9.3,4.8-16.9)$ \\
* ${ }^{*}$ Compared with normal controls. & & & \\
ESCC, esophageal squamous cell cancer. & &
\end{tabular}


A

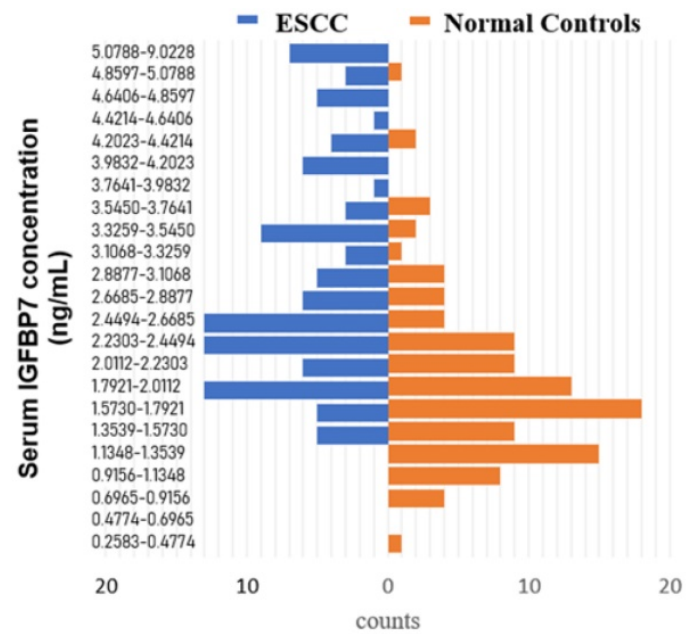

B

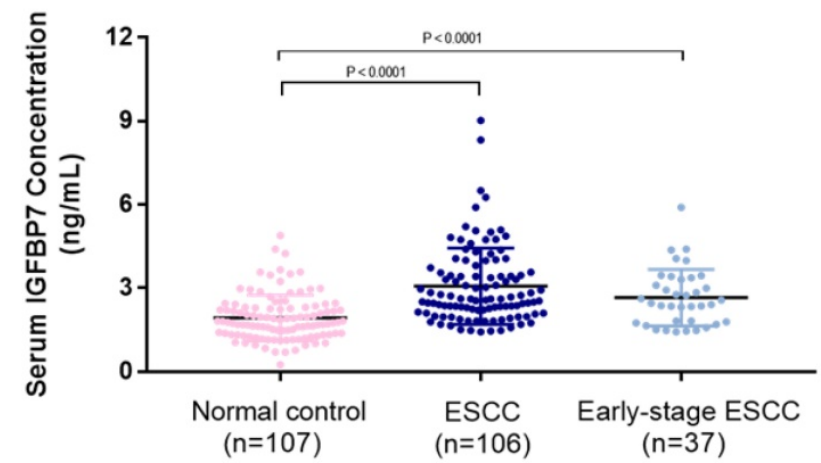

C

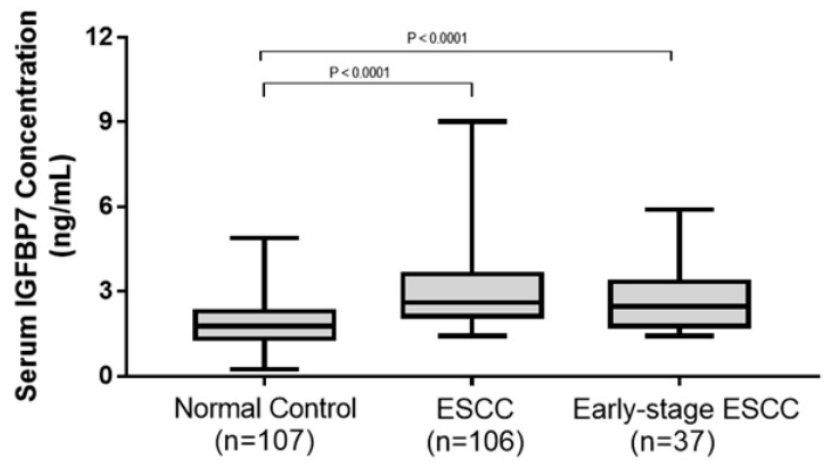

Figure 1. The level of serum in ESCC patient and normal controls. A. The lowest concentration was $0.2583 \mathrm{ng} / \mathrm{mL}$ in normal controls and the highest one was $9.0228 \mathrm{ng} / \mathrm{mL}$ in ESCC. The concentration was divided equally for 40 sections but the sections after 5.0788 $\mathrm{ng} / \mathrm{mL}$ were merged because no sample was more than that in normal controls. The diagram of ESCC is in blue and normal control is in orange. ESCC accounts for more histogram volume on higher concentration while normal groups for more lower concentration. B. The concentration of serum IGFBP7 of every sample in three groups were shown in scatter plot and box plot $(P<0.0001)$. The line in the dots is mean with SD. C. The box plot showed the degree of dispersion. The line in the box is the median. ESCC, esophageal squamous cell cancer. IGFBP7, insulin like growth factor binding protein 7 .

\section{The diagnostic value of IGFBP7 in ESCC and early-stage ESCC}

In accordance to the ROC curve derived from ESCC group versus normal group (Figure 2), the optimized cutoff value of $2.993 \mathrm{ng} / \mathrm{mL}$ was singled out with specificity of $90.7 \%$ and sensitivity of $40.6 \%$.
With the cutoff value, specificity and the sensitivity in early-stage ESCC were $90.7 \%$ and $32.4 \%$, respectively. And the positive rate of ESCC group and early-ESCC group are relatively higher than that of the controls (Table 2). As for the overall diagnostic value, it achieved the AUC of 0.794 for ESCC and 0.725 for early-stage ESCC. For better interpretation on clinical value, we performed false positive rate, false negative rate, positive predictive value, negative predictive value, positive likelihood ratio and negative likelihood ratio, and the result were shown with 95\% CI (Table 3).

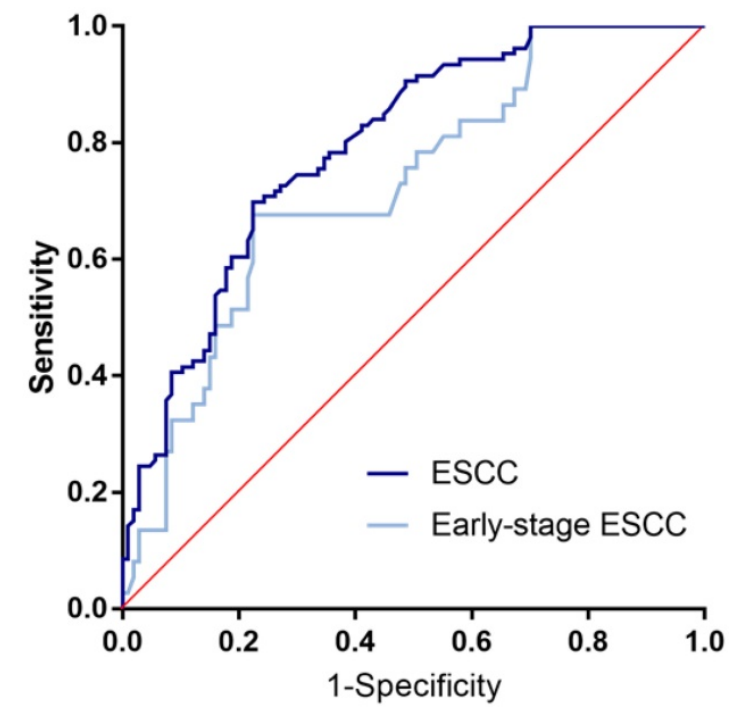

Figure 2. ROC curve analysis in the diagnosis of ESCC and early-stage ESCC. Two groups versus normal controls group are in different colors. The area under the red line is 0.5 , for reference. ROC curve, Receiver operating characteristic curve. ESCC, esophageal squamous cell cancer.

\section{Correlation between serum concentration of IGFBP7 and clinical data in ESCC}

The results of correlation between IGFBP7 level and clinicopathological variables in corresponding subgroups were elaborated (Table 4). There were no statistically significant associations between positive rate of serum IGFBP7 and clinical data, including age, gender, smoking status, drinking status, tumor site, tumor size, depth of tumor invasion, lymph node status, histological grade, and early-stage or advanced-stage of ESCC (all $P>0.05$ ).

\section{Discussion}

In present study, serum IGFBP7 performed a diagnostic value in ESCC with AUC of 0.794, specificity of $90.7 \%$ and sensitivity of $40.6 \%$. As for the early-stage ESCC, certain diagnostic value could be 
observed as well. Since there was no statistic difference between serum IGFBP7 and the clinical data, serum IGFBP7 might be a relative stable marker not affected by the obtained factors but just related to the existence status of the ESCC. As the age of our normal controls and ESCC cases were not well matched, further study could be conducted with corresponding age. But as the result that there is no significant relationship between IGFBP7 and age, the bias of age in two groups could be decreased. Concerning the other indices of diagnostic evaluation, including false positive rate (FPR) of 9.3\% (95\% CI: $4.8 \%-16.9 \%$ ), false negative rate (FNR) of $59.4 \%$ (95\% CI: 49.4\%-68.7\%), positive predictive value (PPV) of $81.1 \%$ (95\%CI: $67.6 \%-90.1 \%$ ), negative predictive value (NPV) of $60.6 \%$ (95\%CI: $52.6 \%-68.2 \%)$, positive likelihood ratio (PLR) of 4.3 (95\%CI: 2.3-8.2), negative likelihood ratio (NLR) of 0.65 (95\%CI: 0.53-0.79), they are for better understanding of the diagnostic value of serum IGFBP7 in ESCC. In addition, as an important parameter for a test used in early detection of cancer, the positive predictive value (PPV) would be 59.1\%, $81.3 \%$ and $92.9 \%$ when standardize disease prevalence of $25 \%, 50 \%$, and $75 \%$ [34], demonstrating that serum IGFBP7 is a promising marker in both low-risk and high-risk area.

Table 3. Evaluation of the detection value of IGFBP7 in the diagnosis of ESCC

\begin{tabular}{|c|c|c|c|c|c|c|c|c|c|}
\hline & AUC & SEN & SPE & FPR & FNR & PPV & NPV & PLR & NLR \\
\hline $\begin{array}{l}\text { ESCC vs. } \\
\text { NC }\end{array}$ & $\begin{array}{l}0.794 \\
(0.735- \\
0.853)\end{array}$ & $\begin{array}{l}40.6 \% \\
(31.3 \%- \\
50.6 \%)\end{array}$ & $\begin{array}{l}90.7 \% \\
(83.1 \%- \\
95.2 \%)\end{array}$ & $\begin{array}{l}9.3 \% \\
(4.8 \%- \\
16.9 \%)\end{array}$ & $\begin{array}{l}59.4 \% \\
(49.4 \%- \\
68.7 \%)\end{array}$ & $\begin{array}{l}81.1 \% \\
(67.6 \%- \\
90.1 \%)\end{array}$ & $\begin{array}{l}60.6 \% \\
(52.6 \%- \\
68.2 \%)\end{array}$ & $\begin{array}{l}4.3 \\
(2.3- \\
8.2)\end{array}$ & $\begin{array}{l}0.65 \\
(0.53- \\
0.79)\end{array}$ \\
\hline $\begin{array}{l}\text { Early-stage } \\
\text { ESCC vs. } \\
\text { NC }\end{array}$ & $\begin{array}{l}0.725 \\
(0.633- \\
0.817)\end{array}$ & $\begin{array}{l}32.4 \% \\
(18.6 \%- \\
49.9 \%)\end{array}$ & $\begin{array}{l}90.7 \% \\
(83.1 \%- \\
95.2 \%)\end{array}$ & $\begin{array}{l}9.3 \% \\
(4.8 \%- \\
16.9 \%)\end{array}$ & $\begin{array}{l}67.6 \% \\
(50.1 \%- \\
81.5 \%)\end{array}$ & $\begin{array}{l}54.5 \% \\
(32.7 \%- \\
74.9 \%)\end{array}$ & $\begin{array}{l}79.5 \% \\
(71.1 \%- \\
86.1 \%)\end{array}$ & $\begin{array}{l}3.5 \\
(1.6- \\
7.4)\end{array}$ & $\begin{array}{l}0.75 \\
(0.60- \\
0.93)\end{array}$ \\
\hline $\begin{array}{l}95 \% \text { CI w } \\
\text { carcinoma } \\
\text { SPE: speci } \\
\text { predictive } \\
\text { NLR: neg }\end{array}$ & 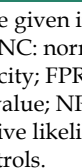 & lo & f & 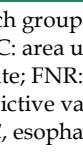 & ГСС & lo & 1 & 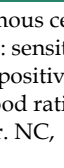 & $\begin{array}{l}\text { itivit } \\
\text { ve } \\
\text { tio; }\end{array}$ \\
\hline
\end{tabular}

Table 4. Correlation between IGFBP7 and clinical data in ESCC patients

\begin{tabular}{lrcc}
\hline & N & Positive $(\%, 95 \% \mathrm{CI})$ & $P$ \\
\hline Age & & & \\
$\geq 60$ & 58 & $26(44.8,32.0-58.4)$ & 0.326 \\
$<60$ & 48 & $17(35.4,22.6-50.6)$ & \\
Gender & & & \\
Male & 75 & $32(42.7,32.1-54.6)$ & 0.493 \\
Female & 31 & $11(35.5,19.8-54.6)$ & \\
Smoke & & & \\
Yes & 68 & $28(41.2,29.6-53.8)$ & 0.864 \\
No & 38 & $15(39.5,24.5-56.6)$ & \\
Tumor Site & & & \\
Upper thorax & 14 & $5(35.7,14.0-64.6)$ & 0.798 \\
Middle thorax & 70 & $30(42.9,31.3-55.2)$ & \\
Low thorax & 22 & $8(36.4,18.0-59.2)$ & \\
Tumor size & & & \\
$\leq 3.8 \mathrm{~cm}$ & 54 & $21(38.9,26.2-53.1)$ & 0.720 \\
$>3.8 \mathrm{~cm}$ & 52 & $22(42.3,29.0-56.7)$ & \\
\hline
\end{tabular}

\begin{tabular}{|c|c|c|c|}
\hline & $\mathrm{N}$ & Positive $(\%, 95 \% \mathrm{CI})$ & $P$ \\
\hline \multicolumn{4}{|c|}{ Depth of tumor invasion (T staging) ${ }^{*}$} \\
\hline $\mathrm{T} 1+\mathrm{T} 2$ & 32 & $10(31.2,16.8-50.1)$ & 0.147 \\
\hline $\mathrm{T} 3+\mathrm{T} 4$ & 71 & $33(46.5,34.7-58.6)$ & \\
\hline \multicolumn{4}{|c|}{ Regional lymph nodes ( $\mathrm{N}$ staging) } \\
\hline No & 58 & $23(39.7,27.3-53.4)$ & 0.834 \\
\hline $\mathrm{N} 1+\mathrm{N} 2+\mathrm{N} 3$ & 48 & $20(41.7,27.9-56.7)$ & \\
\hline \multicolumn{4}{|l|}{ Histological grade } \\
\hline G1 & 31 & $13(41.9,27.1-60.7)$ & 0.331 \\
\hline G2 & 54 & $21(41.9,25.1-60.7)$ & \\
\hline G3 & 13 & $8(61.5,32.3-84.9)$ & \\
\hline \multicolumn{4}{|l|}{ TNM stage } \\
\hline Early-stage $(0+\mathrm{I}+\mathrm{IIA})$ & 37 & $12(32.4,18.6-49.9)$ & 0.212 \\
\hline Advanced stage (IIB+III+IV) & 69 & $31(44.9,33.1-57.3)$ & \\
\hline
\end{tabular}

Similar findings were observed consistent with the result that higher IGFBP7 level is positive correlated to cancers as the present study. The serum level of IGFBP7 is significant higher in soft tissue sarcoma and much higher in the tissue of subgroup with metastasis [35]. Besides, IGFBP7 is positively related to unfavorable clinical variables in gastric cancer [36]. As for colon cancer, IGFBP7 could be a novel tumor stroma marker and promote anchorage-independent growth in malignant mesenchymal cells and in epithelial cells [37]. In contrast with IGFBP7 as an unbeneficial factor, it is wildly accepted that IGFBP7 is a tumor suppressor by influencing the cell proliferation, angiogenesis and other tumor-related activities. It is downregulated in lung cancer [26], ovarian cancer [13] and gastric cancer [38]. As methylation causes gene silencing of IGFBP7, researchers tried to measure the relationship between IGFBP7 methylation and malignance of cancer [38,39], finding that the methylation gave permission to cancer cell proliferation and could develop the tumor. If there is a deletion of IGFBP7, it even promotes the hepatocellular carcinoma [40]. In vitro, IGFBP7 has positive effects on apoptosis in human teratocarcinoma cells ${ }^{[41]}$. Overall, contention on the controversial status of IGFBP7 is inconclusive. The exploration of mechanism may find the answer.

As far as we know, investigation of the detection value of serum IGFBP7 in ESCC has not been done until now. Several researches explored the relationship between IGFBP7 and esophageal cancer, but the detection type, histological type, sample and aim are varied [28-30,42]. Most IGFBP7 studies with relevance to ESCC or other cancers were prone to test samples of cancer tissue and then conducted genetic analysis. However, as a detection method, the marker should be available for clinical use with non-invasive, convenient and cost-effective characteristics, guiding confirmed examination of diagnosis. Therefore, the test of serum IGFBP7 could be a prospective way to promote the clinical use of IGFBP7, and then improve 
the diagnosis of ESCC. In present study, a certain value of IGFBP7 was shown, but several disadvantages did exist, such as the small sample size, single-center research and not well-matched age control group. Therefore, larger trials with well-matched age normal controls are essential for multicenter validation. Since the relationship between IGFBP7 and clinical features is different from that in published paper [36], we ought to validate this doubt on next steps. What's more, the prognostic value could be included in the further study as some researches showed that there is a probable correlation between IGFBP7 and cancer prognosis [36,42]. In addition, as a panel of serum biomarkers could enhance diagnostic efficiency [14,32,43], we could combine serum IGFBP7 with other serum markers or even other types of test to explore the improvement compared to the alone marker.

\section{Conclusion}

In summary, as far as we know, we are the first to date to evaluate the relationship of serum IGFBP7 in the diagnosis of ESCC. Our study demonstrated that serum IGFBP7 is a potential biomarker in the early detection of ESCC.

\section{Abbreviations}

ESCC: esophageal squamous cell cancer; EC: esophageal cancer; IGFBP7: Insulin like growth factor binding protein 7; ELISA: enzyme-linked immunosorbent assay; ROC curve: receiver operating characteristic curve; AUC: area under the ROC curve; OC: ovarian cancer; CEA: carcinoembryonic antigen; SCCA: squamous cell carcinoma antigen; AJCC: American Joint Committee on Cancer; FPR: false positive rate; FNR: false negative rate; PPV: positive predictive value; NPV: negative predictive value; PLR: positive likelihood ratio; NLR: negative likelihood ratio; PPV: positive predictive value; SEN: sensitivity; SPE: specificity; OD: optical density; TMB: 3,3',5,5'-tetramethyl benzidine; HRP: horseradish peroxidase.

\section{Supplementary Material}

Supplementary table.

http://www.jcancer.org/v10p2687s1.xlsx

\section{Acknowledgements}

This work was supported by grants from the National Natural Science Foundation of China (31600632); the Natural Science Foundation of Guangdong Province (2018A030307079); the National Cohort of Esophageal Cancer of China (2016YFC0901400); the Guangdong Esophageal Cancer Institute Science and Technology Program
(M201713); and the Shantou University Medical College Clinical Research Enhancement Initiative (201428).

\section{Competing Interests}

The authors have declared that no competing interest exists.

\section{References}

1. Bray F, Ferlay J, Soerjomataram I, et al. Global cancer statistics 2018: GLOBOCAN estimates of incidence and mortality worldwide for 36 cancers in 185 countries. CA: a cancer journal for clinicians 2018; 68(6): 394-424.

2. Chen W, Sun K, Zheng R, et al. Cancer incidence and mortality in China, 2014. Chin J Cancer Res 2018; 30(1): 1-12.

3. Blot WJ, Tarone RE. Esophageal cancer. In: Thun MJ, Linet MS, Cerhan JR, Haiman CA, Schottenfeld D, eds. Cancer Epidemiology and Prevention. 4th ed. New York: Oxford University Press; 2017 2018:579-592.

4. Arnold M, Soerjomataram I, Ferlay J, Forman D. Global incidence of oesophageal cancer by histological subtype in 2012. Gut 2015; 64(3): 381-387.

5. Torre LA, Bray F, Siegel RL, et al. Global cancer statistics, 2012. CA: a cancer journal for clinicians 2015; 65(2): 87-108.

6. Pennathur A, Gibson MK, Jobe BA, et al. Oesophageal carcinoma. Lancet. 2013; 381: 400-12.

7. Zeng H, Chen $\mathrm{W}$, Zheng $\mathrm{R}$, et al. Changing cancer survival in China during 2003-15: a pooled analysis of 17 population-based cancer registries. The Lancet Global Health. 2018; 6: e555-e67.

8. Enzinger PC, Mayer RJ. Esophageal cancer. N Engl J Med. 2003; 349: 2241-52.

9. Sturgeon CM, Lai LC, Duffy MJ. Serum tumour markers: how to order and interpret them. Bmi 2009; 339: b3527.

10. Gaddam S, Edmundowicz SA. Endoscopic tumor diagnosis and treatment. Gastrointest Endosc 2013; 78(3): 421-427.

11. European Colorectal Cancer Screening Guidelines Working G, von Karsa L, Patnick J, et al. European guidelines for quality assurance in colorectal cancer screening and diagnosis: overview and introduction to the full supplement publication. Endoscopy. 2013; 45: 51-9.

12. Hosokawa O, Miyanaga T, Kaizaki $Y$, et al. Decreased death from gastric cancer by endoscopic screening: association with a population-based cancer registry. Scand J Gastroenterol 2008; 43(9): 1112-1115.

13. Russell MR, Walker MJ, Williamson AJ, et al. Protein Z: A putative novel biomarker for early detection of ovarian cancer. International journal of cancer 2016; 138(12): 2984-2992.

14. Patz EF, Jr., Campa MJ, Gottlin EB, et al. Panel of serum biomarkers for the diagnosis of lung cancer. Journal of clinical oncology: official journal of the American Society of Clinical Oncology 2007; 25(35): 5578-5583.

15. Zanotti L, Paderno A, Piazza C, et al. Epidermal growth factor receptor detection in serum and saliva as a diagnostic and prognostic tool in oral cancer. Laryngoscope 2017; 127(11): E408-E414.

16. Song YF, Xu ZB, Zhu XJ, et al. Serum Cyr61 as a potential biomarker for diagnosis of colorectal cancer. Clinical \& translational oncology: official publication of the Federation of Spanish Oncology Societies and of the National Cancer Institute of Mexico 2017; 19(4): 519-524.

17. Tsuchiya N, Sawada Y, Endo I, et al. Biomarkers for the early diagnosis of hepatocellular carcinoma. World J Gastroenterol 2015; 21(37): 10573-10583.

18. Wong RJ, Ahmed A, Gish RG. Elevated alpha-fetoprotein: differential diagnosis - hepatocellular carcinoma and other disorders. Clinics in liver disease 2015; 19(2): 309-323.

19. Duffy MJ, Lamerz R, Haglund C, et al. Tumor markers in colorectal cancer, gastric cancer and gastrointestinal stromal cancers: European group on tumor markers 2014 guidelines update. International journal of cancer 2014; 134(11): 2513-2522.

20. Goonetilleke KS, Siriwardena AK. Systematic review of carbohydrate antigen (CA 19-9) as a biochemical marker in the diagnosis of pancreatic cancer. Eur J Surg Oncol 2007; 33(3): 266-270.

21. Fong ZV, Winter JM. Biomarkers in pancreatic cancer: diagnostic, prognostic, and predictive. Cancer J. 2012; 18: 530-8.

22. Nakamura T, Ide H, Eguchi R, et al. CYFRA 21-1 as a tumor marker for squamous cell carcinoma of the esophagus. Dis Esophagus. 2017; 11: 35-9.

23. Zheng X, Xing S, Liu XM, et al. Establishment of using serum YKL-40 and SCCA in combination for the diagnosis of patients with esophageal squamous cell carcinoma. BMC Cancer. 2014; 14: 490.

24. Kawaguchi H, Ohno S, Miyazaki M, et al. CYFRA 21-1 determination in patients with esophageal squamous cell carcinoma: clinical utility for detection of recurrences. Cancer. 2000; 89: 1413-7.

25. Evdokimova V, Tognon CE, Benatar T, et al. IGFBP7 binds to the IGF-1 receptor and blocks its activation by insulin-like growth factors. Sci Signal 2012; 5(255): ra92.

26. Wang Z, Wang Z, Liang Z, et al. Expression and clinical significance of IGF-1, IGFBP-3, and IGFBP-7 in serum and lung cancer tissues from patients with non-small cell lung cancer. Onco Targets Ther. 2013; 6: 1437-44. 
27. Sullivan L, Murphy TM, Barrett C, et al. IGFBP7 promoter methylation and gene expression analysis in prostate cancer. The Journal of urology 2012; 188(4): 1354-1360.

28. Kashyap MK, Pawar HA, Keerthikumar S, et al. Evaluation of protein expression pattern of stanniocalcin 2, insulin-like growth factor-binding protein 7 , inhibin beta A and four and a half LIM domains 1 in esophageal squamous cell carcinoma. Cancer Biomark 2012; 12(1): 1-9.

29. Chen $Y B$, Liao $X Y$, Zhang JB, et al. ADAR2 functions as a tumor suppressor via editing IGFBP7 in esophageal squamous cell carcinoma. Int J Oncol 2017; 50(2): 622-630.

30. Warnecke-Eberz U, Metzger R, Holscher AH, et al. Diagnostic marker signature for esophageal cancer from transcriptome analysis. Tumour Biol 2016; 37(5): 6349-6358.

31. Rice TW, Gress DM, Patil DT, et al. Cancer of the esophagus and esophagogastric junction-Major changes in the American Joint Committee on Cancer eighth edition cancer staging manual. CA: a cancer journal for clinicians 2017; 67(4): 304-317.

32. Xu YW, Peng YH, Chen B, et al. Autoantibodies as potential biomarkers for the early detection of esophageal squamous cell carcinoma. Am J Gastroenterol 2014; 109(1): 36-45.

33. Boyle $\mathrm{P}$, Chapman CJ, Holdenrieder $\mathrm{S}$, et al. Clinical validation of an autoantibody test for lung cancer. Ann Oncol. 2011; 22: 383-9.

34. Heston TF. Standardized predictive values. J Magn Reson Imaging. 2014; 39: 1338.

35. Benassi MS, Pazzaglia L, Novello C, et al. Tissue and serum IGFBP7 protein as biomarker in high-grade soft tissue sarcoma. Am J Cancer Res. 2015; 5: 3446-54.

36. Sato Y, Inokuchi M, Takagi Y, et al. Relationship between expression of IGFBP7 and clinicopathological variables in gastric cancer. J Clin Pathol 2015; 68(10): 795-801.

37. Rupp C, Scherzer M, Rudisch A, et al. IGFBP7, a novel tumor stroma marker, with growth-promoting effects in colon cancer through a paracrine tumor-stroma interaction. Oncogene 2015; 34(7): 815-825.

38. Kim J, Kim WH, Byeon SJ, et al. Epigenetic Downregulation and Growth Inhibition of IGFBP7 in Gastric Cancer. Asian Pacific journal of cancer prevention : APJCP 2018; 19(3): 667-675.

39. Suzuki M, Shiraishi K, Eguchi A, et al. Aberrant methylation of LINE-1, SLIT2, MAL and IGFBP7 in non-small cell lung cancer. Oncology reports 2013; 29(4): 1308-1314.

40. Akiel M, Guo C, Li X, et al. IGFBP7 Deletion Promotes Hepatocellular Carcinoma. Cancer research 2017; 77(15): 4014-4025.

41. Engstrom W. Effects of insulin-like growth factor binding protein 7 on apoptosis in human teratocarcinoma cells in vitro. Anticancer Res. 2010; 30: 911-4.

42. Smith E, Ruszkiewicz AR, Jamieson GG, et al. IGFBP7 is associated with poor prognosis in oesophageal adenocarcinoma and is regulated by promoter DNA methylation. British journal of cancer 2014; 110(3): 775-782.

43. Xu YW, Chen $\mathrm{H}$, Guo HP, et al. Combined detection of serum autoantibodies as diagnostic biomarkers in esophagogastric junction adenocarcinoma. Gastric cancer: official journal of the International Gastric Cancer Association and the Japanese Gastric Cancer Association 2018. 